\title{
Optimization of methanol extraction parameters for total flavonoids from onion processing waste
}

\author{
Tsvetko Prokopov, Milena Nikolova ${ }^{1, *}$, Stanislava Tasheva $^{2}$, and Donka Taneva ${ }^{1}$ \\ ${ }^{1}$ Department of Engineering Ecology, University of Food Technologies, Plovdiv, Bulgaria \\ ${ }^{2}$ Department of Heat Engineering, University of Food Technologies, Plovdiv, Bulgaria
}

\begin{abstract}
Onion processing generates large amount of solid waste. Due to the high amount of biologically active substances the onion processing residues could be interesting source of value-added functional ingredients. In this study the response surface methodology was applied to explore the possibilities of modelling and optimization of the methanol extraction of total flavonoids from onion processing waste. The extraction temperature, time and solvent concentration were first optimized employing Box-Behnken design and then the extraction efficiency was further assessed through kinetics. The optimal extraction conditions were determined to be $53^{\circ} \mathrm{C}, 66 \mathrm{~min}$ and $61 \%$ of methanol concentration. Data indicated that predicted (15.54 $\left.\mathrm{mgQE} \mathrm{g}^{-1} \mathrm{dw}\right)$ and experimental $\left(15.58 \pm 0.03 \mathrm{mgQE} \mathrm{g}^{-1} \mathrm{dw}\right)$ values of total flavonoids were not significant different $(\mathrm{p}>0.05)$. The kinetics and thermodynamic parameters of the extraction process were determined also.
\end{abstract}

\section{Introduction}

Agricultural and food sectors generated great amount of waste bio-mass. The bio-economy concept includes the implementation of alternative strategies for the production of high value-added substances. Nowadays, food waste accounts as a source of valuable nutraceuticals. Significant volume and availability of the bio-waste and their low cost and richness in bio-active substances convert them to a valuable resource for bio-refinery. Over the last years, there have been an increasing number of studies dealing with polyphenol extraction from plant tissue. However, the extraction of phytochemicals from onion waste is very limited $[1,2]$.

Onion is one of the most important vegetable crops grown worldwide and is the most common and richest natural source of flavonoids. Among flavonoids present in the onion, quercetin is well-known major component [37]. The increase of the production and consumption of onion leading to increases of onion waste. About $37 \%$ of fresh onions are discarded during processing as waste. The onion processing waste (OPW) includes onion skins, generated during peeling operation, two outer fleshy scales, roots, top and bottom of the bulbs and also undersized malformed diseased or damaged bulbs. These onion wastes are converted to real problem from the industrial and ecological point of view. Thus, the valorization of OPW has been of the great interest in the recent years to promote its profitable usage and to convert them into value-added products and food ingredients [6$8]$.

Conventional solvent extraction is commonly used in food sector and pharmaceutical industry. However, the efficiency of extraction of phytochemicals from plant materials depends on the process conditions used, such as temperature, time, type and concentration of the solvent in the mixture. In the research work presented in the literature total flavonoids (TF) have been extracted from onion skin by conventional solvent extraction with the use of mainly aqueous ethanol. But the removal of water from the extract is highly energy-intensive and the cost of ethanol is relatively high. On the other side methanol has lower boiling point compare to ethanol and could be easily vaporizes after extraction in order to obtained dried extract free from methanol, which can be used in the practice. The use of methanol to extraction of phytochemicals from onion waste is fully justified $[5,8$, 9].

Many studies related to modelling and optimization of the extraction process of phytochemicals from onion waste, including Box-Behnken design (BBD) in response surface methodology (RSM) as a statistical tool, have been reported recently $[2,5,8,11-13]$. Moreover, the kinetic modelling of the extraction of polyphenols from OPW was used also for assessing the extraction efficiency [14].

However, the information on the literature regarding optimization of methanol extraction of TF from OPW is not enough. Therefore, this study aimed to applied RSM approach and $\mathrm{BBD}$ for investigation the possibility of modelling and optimization of methanol extraction parameters for TF from Bulgarian OPW and the assessing the extraction efficiency through kinetics.

\footnotetext{
* Corresponding author: milena nikolova86@abv.bg
} 


\section{Materials and methods}

\subsection{Sample preparation}

The Bulgarian OPW sample was obtained and prepared as described in our previous study [7].

\subsection{Extraction of TF}

The methanol extraction of TF from OPW was performed in $250 \mathrm{ml}$ conical glass flask placed into temperaturecontrolled water bath as described by [15], with modifications. Briefly, OPW sample (1.00 g) was placed in extraction flask and was stirred with methanol at different conditions (Table 2) by magnetic stirrer (VELP Scientifica, Italy) at $400 \mathrm{rpm}$. Solid-to-liquid ratio was fixed to $1: 40 \mathrm{w} / \mathrm{v}$ on the base of preliminary experiments carried out. The obtained extract was vacuum filtered through MN640de filter paper and was subjected to TF analysis [15].

\subsection{TF analysis}

The total flavonoids content (TFC) in quercetin equivalents (mgQE g-1 d.w.) of the obtained extracts was determined spectrophotometrically (UV-VIS Helios Omega, USA) at $415 \mathrm{~nm}$ and HPLC analysis of flavonoids was performed (Waters, Milford, MA, USA) as described in our previous study [7].

\subsection{Experimental design}

Three-variable, three-level BBD of RSM (Table 2) was applied in modelling and optimization the methanol extraction process for highest recovery of TFC from Bulgarian OPW with 18 runs, including 6 replicates at the center points $[15,16]$. Independent variables are presented in Table 1 and their ranges were determined on the base of preliminary study. The experiments were run in triplicate and the average TFC was taken as response function ( $\mathrm{Y}, \mathrm{mgQE} \mathrm{g}^{-1}$ d.w.). The regression model was used to fit the experimental data as described by [15]. Optimized extraction conditions were verified by performing of additional experiments in triplicate. Statistical analysis including analysis of variance (ANOVA), F-test and p-value at 5\% significance level were conducted for determination of model significance. The adequacy of obtained model was evaluated by coefficient of determination $\left(\mathrm{R}^{2}\right)$ and adjusted coefficient of determination ( $\mathrm{R}^{2}$ adj) [15].

\subsection{Kinetics study}

Conventional methanol extraction of TF from OPW was carried out as described above at optimal extraction conditions determined by applied RSM. Sampling was accomplished at regular intervals (Table 4) and after filtering the obtained extracts were used for TFC determination. Kinetic modelling and calculations of the kinetic and thermodynamic parameters were conducted according to the equations presented in the literature [1622].

Table 1. Independent variables with their codded and actual levels applied in BBD.

\begin{tabular}{|l|c|c|c|}
\hline \multirow{2}{*}{ Independent variables } & \multicolumn{3}{|c|}{ Levels } \\
\cline { 2 - 4 } & $\mathbf{- 1}$ & $\mathbf{0}$ & $+\mathbf{1}$ \\
\hline Temperature $\left(\mathbf{x}_{\mathbf{1}},{ }^{\circ} \mathbf{C}\right)$ & 25 & 40 & 55 \\
\hline Time $\left(\mathbf{x}_{\mathbf{2}}, \mathbf{m i n}\right)$ & 10 & 60 & 110 \\
\hline Methanol concentration $\left(\mathbf{x}_{\mathbf{3}}, \mathbf{\%} \%\right)$ & 30 & 60 & 90 \\
\hline
\end{tabular}

Table 2. Experimental BBD with the observed values of TFC.

\begin{tabular}{|c|c|c|c|c|}
\hline \multirow[t]{2}{*}{ Run } & \multicolumn{3}{|c|}{ Coded variable levels } & \multirow{2}{*}{$\begin{array}{c}\text { TFC }^{*} \\
\left(\mathrm{mgQE}, \mathrm{g}^{-1} \text { d.w.) }\right.\end{array}$} \\
\hline & $\mathbf{x}_{1}$ & $\mathbf{x}_{2}$ & $\mathbf{x}_{3}$ & \\
\hline 1 & 0 & 0 & 0 & $14.98 \pm 0.01$ \\
\hline 2 & 0 & -1 & -1 & $9.54 \pm 0.01$ \\
\hline 3 & -1 & 0 & -1 & $9.07 \pm 0.02$ \\
\hline 4 & 1 & -1 & 0 & $13.76 \pm 0.04$ \\
\hline 5 & 0 & 0 & 0 & $14.98 \pm 0.02$ \\
\hline 6 & 1 & 1 & 0 & $14.67 \pm 0.04$ \\
\hline 7 & 0 & 0 & 0 & $15.05 \pm 0.02$ \\
\hline 8 & -1 & 1 & 0 & $11.65 \pm 0.01$ \\
\hline 9 & 1 & 0 & 1 & $12.05 \pm 0.03$ \\
\hline 10 & -1 & -1 & 0 & $11.52 \pm 0.02$ \\
\hline 11 & 0 & 1 & 1 & $12.23 \pm 0.01$ \\
\hline 12 & 0 & 0 & 0 & $15.00 \pm 0.02$ \\
\hline 13 & 0 & 0 & 0 & $15.02 \pm 0.02$ \\
\hline 14 & 0 & -1 & 1 & $10.77 \pm 0.02$ \\
\hline 15 & -1 & 0 & 1 & $11.25 \pm 0.08$ \\
\hline 16 & 1 & 0 & -1 & $12.67 \pm 0.01$ \\
\hline 17 & 0 & 1 & -1 & $9.72 \pm 0.02$ \\
\hline 18 & 0 & 0 & 0 & $15.00 \pm 0.02$ \\
\hline
\end{tabular}

*Mean of triplicate determinations \pm standard deviation (SD).

\section{Results and discussion}

\subsection{Optimization of TF extraction from OPW}

The impact of three variables, such as extraction temperature $\left(\mathrm{x}_{1}\right)$, extraction time $\left(\mathrm{x}_{2}\right)$ and methanol concentration $\left(\mathrm{x}_{3}\right)$, that are essential for the TF extraction efficiency, was tested and the results obtained under the operational conditions are presented in Table 2. Based on the results from implementation of BBD in RSM the following regression model was found to best fit of experimental data:

$$
\begin{gathered}
\mathrm{Y}=15.005+1.2075 \cdot \mathrm{x}_{1}+0.335 \cdot \mathrm{x}_{2}+0.6625 . \mathrm{x}_{3}- \\
0.7 \cdot \mathrm{x}_{1} \cdot \mathrm{x}_{3}-0.705 \cdot \mathrm{x}_{1}{ }^{2}-1.4 \cdot \mathrm{x}_{2}{ }^{2}-3.04 \cdot \mathrm{x}_{3}{ }^{2}
\end{gathered}
$$

The high values obtained for $\mathrm{R}^{2}(0.983)$ and $\mathrm{R}^{2}$ adj (0.972) confirmed the model adequacy and therefore this model could be used to predict the extraction efficiency and for optimization. Data for assessment of the model validity by ANOVA are presented in Table 3 . The F-value calculated implies the model was significant and the pvalues less than 0.05 indicate that linear terms $\left(\mathrm{x}_{1}, \mathrm{x}_{2}\right.$ and $\left.\mathrm{x}_{3}\right)$, interaction term $\left(\mathrm{x}_{1} \mathrm{x}_{3}\right)$ and quadratic terms $\left(\mathrm{x}_{1}{ }^{2}, \mathrm{x}_{2}{ }^{2}\right.$ and $\left.\mathrm{x}_{3}{ }^{2}\right)$ are significant. The interaction terms $\left(\mathrm{x}_{1}, \mathrm{x}_{2}\right)$ and $\left(\mathrm{x}_{2} \mathrm{x}_{3}\right)$ were found to be statistically insignificant $(\mathrm{p}>$ 
0.05). Other research also reported adequate fitting of the experimental data to second-order regression model [8, 24].

The results indicated that extraction temperature was the most significant linear term variable positive affected the TF extraction from OPW, followed by methanol concentration and extraction time. This is in accordance with previous investigations indicated that the increasing of temperature favors extraction because of enhancing solubility of the substances and increasing the diffusion coefficient [24, 25].

The quadratic terms showed the high significant negative effect on studied response, having the highest effect of methanol concentration. The combined effect of the three independent variables on the TFC was recorded by the response-surface plots presented in Fig.1, 2 and 3.

Table 3. ANOVA for extraction of TFC from OPW.

\begin{tabular}{|c|c|c|c|c|c|}
\hline Source & $\begin{array}{c}\text { Sum of } \\
\text { Squires }\end{array}$ & Df & $\begin{array}{c}\text { Mean } \\
\text { Squire }\end{array}$ & F-ratio & P-value \\
\hline $\mathbf{x} 1$ & 11.6644 & 1 & 11.6644 & 89.95 & 0.00001 \\
\hline $\mathbf{x}_{2}$ & 0.8978 & 1 & 0.8978 & 6.92 & 0.0251 \\
\hline $\mathbf{x}_{3}$ & 3.51125 & 1 & 3.51125 & 27.08 & 0.0004 \\
\hline $\mathbf{x 1}^{\mathbf{2}}$ & 2.16884 & 1 & 2.16884 & 16.73 & 0.0022 \\
\hline $\mathbf{x}_{\mathbf{1} 3} \mathbf{3}$ & 1.9600 & 1 & 1.9600 & 15.11 & 0.0030 \\
\hline $\mathbf{x 2}^{\mathbf{2}}$ & 8.5527 & 1 & 8.5527 & 65.96 & 0.00001 \\
\hline $\mathbf{x}_{\mathbf{3}}^{\mathbf{2}}$ & 40.3270 & 1 & 40.3270 & 310.99 & 0.00001 \\
\hline $\begin{array}{c}\text { Total } \\
\text { error }\end{array}$ & 1.2968 & 10 & 0.12968 & - & - \\
\hline $\begin{array}{c}\text { Total } \\
\text { (corr.) }\end{array}$ & 77.8896 & 17 & - & - & - \\
\hline
\end{tabular}

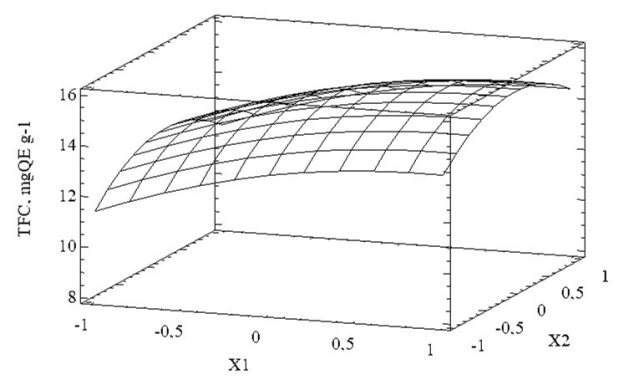

Fig. 1. Response-surface plot of the effects of extraction temperature $\left(\mathrm{X}_{1}\right)$ and extraction time $\left(\mathrm{X}_{2}\right)$ at $60 \%$ methanol concentration on TFC $\left(\mathrm{mgQE} \mathrm{g}^{-1}\right)$.

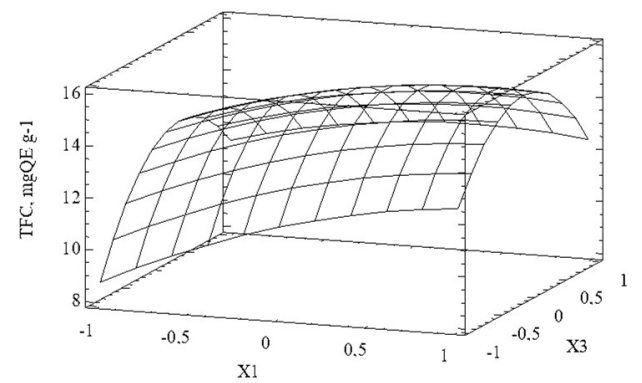

Fig. 2. Response-surface plot of the effects of extraction temperature $\left(\mathrm{X}_{1}\right)$ and methanol concentration $\left(\mathrm{X}_{3}\right)$ at $60 \mathrm{~min}$ extraction time on TFC (mgQE g $\left.{ }^{-1}\right)$.

The validation of the determined second-order regression model for extraction of TF from OPW was carried out by the optimized extraction conditions obtained by RSM application. The results indicated maximum TFC of $15.54 \mathrm{mgQE} \mathrm{g}^{-1}$ d.w., which was achieved at extraction temperature $53^{\circ} \mathrm{C}$, extraction time $66 \mathrm{~min}$ and $61 \%$ methanol concentration. Piechowiak et al. [8] reported methanol extraction of total polyphenols from yellow onion skin in the range from 16.4 to 34.5 mgQE $g^{-1}$.

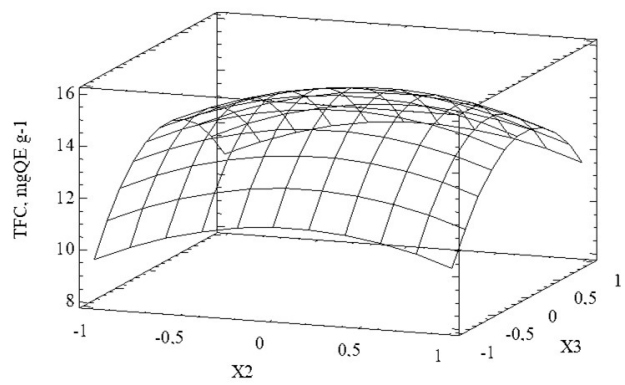

Fig. 3. Response-surface plot of the effects of extraction time (x2) and methanol concentration ( $\left.\mathrm{x}_{3}\right)$ at $40^{\circ} \mathrm{C}$ extraction temperature on TFC (mgQE g $\left.{ }^{-1}\right)$.

Additional experiments at optimized conditions were carried out in our study for obtained regression model verification and validation. The average TFC determined from triplicate experiments was $15.58 \pm 0.03 \mathrm{mgQE} \mathrm{g}^{-1}$ d.w., which was very closed to the RSM predicted value, within the limits set by our investigation. The total extract yield obtained under the optimized conditions was $9.8 \mathrm{~g}$ $100 \mathrm{~g}^{-1}$ d.w., which is in accordance with the results reported for methanol extraction of total polyphenols from onion skin [8].

The content of individual flavonoids in the obtained methanol extract was determined by HPLC and the results

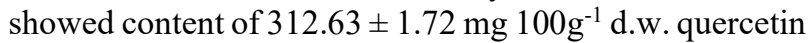
and also presence of hesperetin, luteolin, apigenin and kaempferol. This is in agreement with our previous research [7]. In another study presented content of quercetin by ethanol extraction from onion skin has been

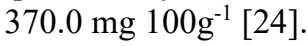

\subsection{Kinetics study}

Table 4 presents the kinetic parameters of the TF extraction from OPW under optimized conditions. The extraction from plant raw materials obeys the laws of diffusion and one of the main parameters is the diffusion coefficient. The diffusion coefficient was determined by the equations of Minosyan $\left(\mathrm{D}_{1}\right)$, Wilke-Chang $\left(\mathrm{D}_{2}\right)$ and Stoke's-Einstein $\left(\mathrm{D}_{3}\right)$ and the effective diffusion coefficient $\left(D_{e}\right)$ was also determined according to the Arrhenius equation [19, 23].

Data in Table 4 indicated that the diffusion coefficient $\left(D_{1}\right)$, calculated according to the Minosyan equation, decreases with increasing extraction time, which means that the extracted TF decrease in the raw material (OPW). The constant values of the diffusion coefficients calculated according to the Wilke-Chang and Stoke'sEinstein equations could be explained by the solvent used and the temperature at which the diffusion takes place. Therefore, these equations do not reflect the diffusion coefficient very accurately. The effective diffusion 
coefficient $\left(\mathrm{D}_{\mathrm{e}}\right)$ calculated according to the obtained results for the molecular internal diffusion also decreases with increasing duration of the extraction process, which is logical since the extraction of $\mathrm{TF}$ decreases with increasing extraction time. Similar results have been reported by another research [23].

Table 4. Kinetic parameters of TF extraction from OPW.

\begin{tabular}{|c|c|c|c|c|c|c|}
\hline $\begin{array}{c}\text { Extraction } \\
\text { time }(t), s\end{array}$ & 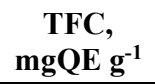 & $\mathrm{k} 10^{3}, \mathrm{dm}^{3} \mathrm{~s}^{-1}$ & $D_{1} 10^{6}, m^{2} s^{-1}$ & $D_{2} 10^{6}, m^{2} s^{-1}$ & $D_{3} 10^{12}, \mathrm{~m}^{2} \mathrm{~s}^{-1}$ & $D_{\mathrm{e}} 10^{6}, \mathrm{~m}^{2} \mathrm{~s}^{-1}$ \\
\hline 300 & 13.05 & 0.25 & 0.83 & 0.12 & 3.15 & 8.31 \\
\hline 600 & 14.14 & 0.12 & 0.81 & 0.12 & 3.15 & 8.16 \\
\hline 900 & 14.75 & 0.07 & 0.81 & 0.12 & 3.15 & 8.08 \\
\hline 1800 & 15.14 & 0.04 & 0.80 & 0.12 & 3.15 & 8.03 \\
\hline 2700 & 15.44 & 0.02 & 0.80 & 0.12 & 3.15 & 7.99 \\
\hline 3960 & 15.58 & 0.02 & 0.79 & 0.12 & 3.15 & 7.97 \\
\hline
\end{tabular}

$\mathrm{k}$ - rate constant for extraction of TF from OPW; $\mathrm{D}_{1}-$ molecular internal diffusion coefficient calculated by the Minosyan equation; $\mathrm{D}_{2}-$ diffusion coefficient calculated according to the Wilke-Chang equation; $\mathrm{D}_{3}$ - diffusion coefficient calculated by the Stoke's-Einstein equation; $\mathrm{D}_{\mathrm{e}}-$ effective diffusion coefficient.

Table 5. Thermodynamic parameters of intermediate and final state of TF extraction from OPW.

\begin{tabular}{|c|c|c|c|c|c|c|c|}
\hline $\begin{array}{c}\text { Extraction } \\
\text { time }(t), s\end{array}$ & $\begin{array}{c}\text { TFC, } \\
{\text { mgQE } \text { g }^{-1}}^{-}\end{array}$ & $\begin{array}{c}\mathbf{G}^{\#}, \\
\text { kJ mol }^{-1} \\
\end{array}$ & $\begin{array}{c}\mathrm{S}^{\#}, \\
\mathbf{k J} \mathbf{m o l}^{-1} \mathbf{k}^{-1}\end{array}$ & $\begin{array}{c}\mathbf{H}^{\#}, \\
\mathrm{~kJ} \mathrm{~mol}^{-1} \\
\end{array}$ & $\begin{array}{c}\mathbf{G}, \\
\mathrm{kJ} \mathrm{mol}^{-1} \\
\end{array}$ & $\begin{array}{c}\mathrm{S}, \\
\mathrm{kJ} \text { mol }^{-1}\end{array}$ & $\begin{array}{c}\mathrm{H}, \\
\mathrm{kJ} \mathrm{mol}^{-1}\end{array}$ \\
\hline 300 & 13.05 & -9108 & -55.39 & -8956 & 11730 & 55.11 & 6245 \\
\hline 600 & 14.14 & -9108 & -55.39 & -8956 & 11509 & 54.44 & 6245 \\
\hline 900 & 14.75 & -9108 & -55.39 & -8956 & 11393 & 54.08 & 6245 \\
\hline 1800 & 15.14 & -9108 & -55.39 & -8956 & 11321 & 53.86 & 6245 \\
\hline 2700 & 15.44 & -9108 & -55.39 & -8956 & 11267 & 53.69 & 6245 \\
\hline 3960 & 15.58 & -9108 & -55.39 & -8956 & 11243 & 53.62 & 6245 \\
\hline
\end{tabular}

$\mathrm{G}^{\#}$ - Gibbs free energy of the intermediate state; $\mathrm{S}^{\#}$ - entropy of the intermediate state; $\mathrm{H}^{\#}$ - enthalpy of the intermediate state; $\mathrm{G}$ - Gibbs free energy of the final state; $\mathrm{S}$ - entropy of the final state; $\mathrm{H}$ - enthalpy of the final state.

Activation energy is a characteristic of a chemical reaction that indicates the minimum energy that molecules must possess in order to interact and to carry out a process. The value obtained for activating energy in our study was $\mathrm{Ea}=-6245 \mathrm{~kJ} \mathrm{~mol}^{-1}$. The negative value of activating energy could be explained by the fact that in order to carry out the extraction process it is necessary to import energy [22].

According to the Arrhenius equation, the reaction step constant of the process could be determined, which is a kinetic characteristic of an extraction process. The reaction constant of the extraction of TF from OPW was $0.867 \times 10^{9} \mathrm{~min}^{-1}$. The order of the reaction of TF extraction from the raw material was calculated by using the values obtained for the TFC, according to the differential method [26, 27]. The reaction was of the second-order. The calculated rate constant $\left(\mathrm{k}, \mathrm{dm}^{3} \mathrm{~s}^{-1}\right)$ of the reaction varied from 0.02 to 0.25 (Table 4). Makris and Kefalas also reported second-order kinetics for the extraction of polyphenols from onion solid waste [14].

Table 5 presents the thermodynamic parameters of the TF extraction from OPW under optimized conditions.

Data indicated that the system is the most stable in the intermediate state from thermodynamic point of view. The Gibbs free energy $\left(\mathrm{G}^{\#}\right)$, enthalpy $\left(\mathrm{H}^{\#}\right)$ and entropy $\left(\mathrm{S}^{\#}\right)$ values are negative, which means that the process is irreversible and does not occur spontaneously. Therefore, heat input is required for the extraction process. These are in accordance with another published research $[18,20]$.

Based on the determined thermodynamic parameters of the final state, could be concluded that the process proceeds spontaneously and is irreversible because of the Gibbs energy $(G)$ values were positive. The obtained positive values for the enthalpy $(\mathrm{H})$ of the process, which is equal to the activating energy $(\mathrm{Ea})$ with the inverse sign, mean that the process is energy consuming. The decreasing values of entropy (S) with increasing extraction time $(\mathrm{t})$ at the same temperature could be explained by the associative mechanism, the degrees of freedom due to the activation complex, and more precisely the mechanism of the reaction that occurs in the process itself. Similar results have been reported by others [19, 21, 28, 29].

Figure 4 shows graphical dependence between the degree of extraction $(\eta)$ and the extraction time $(t)$. The results were calculated $\left(\mathrm{R}^{2}=0.849\right)$ by the following equation:

$$
\eta=98.68-1.37 \cdot 10^{-4} \cdot \mathrm{t}+1.81 \cdot 10^{-8} \cdot \mathrm{t}^{2}
$$

The degree of extraction was calculated on the basis of the concentration of the extracted TF from the amount of $\mathrm{TF}$ in the raw material. The obtained degree of extraction gives information about the efficiency of the process. The values were in the range from $98.4 \%$ to $98.7 \%$, which means that the extracted TF from OPW were in the maximum amount.

The same was proved by the calculated coefficient of extraction (Fig. 5). The following equation was obtained for calculation of coefficient of extraction (CE):

$\mathrm{CE}=0.013+1.41 \cdot 10^{-6} \cdot \mathrm{t}-1.86 \cdot 10^{-10} \cdot \mathrm{t}^{2}$ 


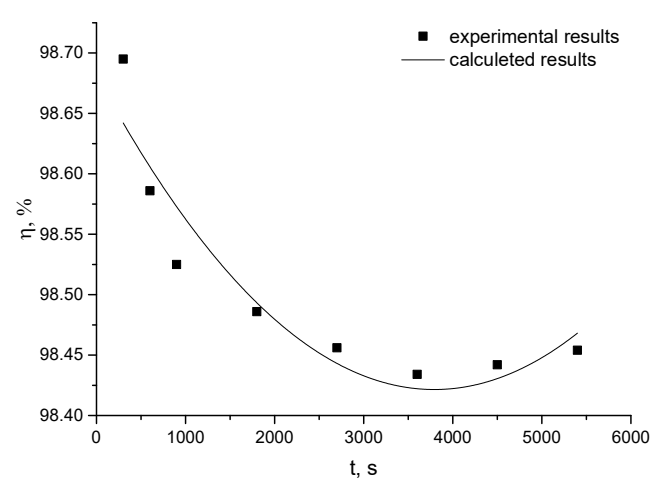

Fig. 4. Degree of extraction $(\eta, \%)$ depending on the time of extraction $(\mathrm{t}, \mathrm{s})$ of TF from OPW.

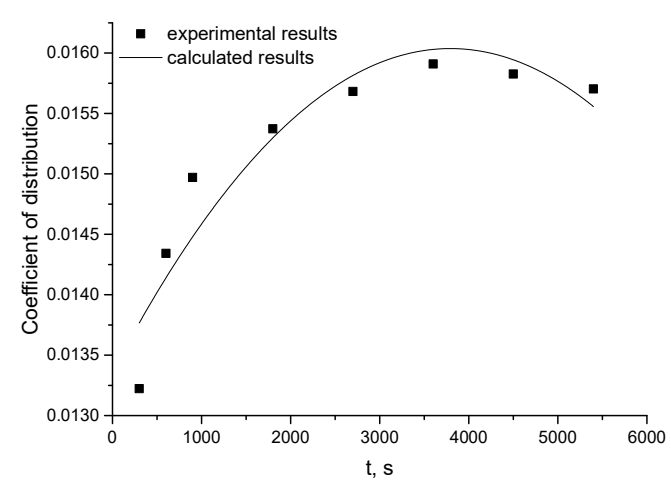

Fig. 5. Coefficient of extraction depending on the time of extraction $(t, s)$ of TF from OPW.

\section{Conclusions}

Optimal conditions for methanol extraction of TF from Bulgarian OPW were determined by development of BBD in RSM. The effects of extraction temperature, extraction time and methanol concentration on TFC were found to be statistically significant $(\mathrm{p}<0.05)$ applying of ANOVA. The second-order regression model was developed and used in prediction of the response function (TFC, $\mathrm{mgQE} \mathrm{g}^{-1} \mathrm{~d}$.w.). The established optimal extraction conditions for maximal TFC were $53^{\circ} \mathrm{C}, 66$ min and $61 \%$ methanol concentration. Model validation was carried out and the obtained predicted (15.54 mgQE g ${ }^{-1} \mathrm{~d} . \mathrm{w}$.) and experimental $\left(15.58 \pm 0.03 \mathrm{mgQE} \mathrm{g}^{-1} \mathrm{~d} . \mathrm{w}\right.$.) values of TFC were not significant different $(\mathrm{p}>0.05)$. Therefore, the developed model could be used for prediction of TFC extracted from OPW at the experimental range of extraction conditions. The kinetics and thermodynamic parameters of the extraction process were determined also. Based on the kinetic study the extraction of TF from Bulgarian OPW was found to obey second-order kinetics. The obtained dried extract of TF from Bulgarian OPW could be used as additive for functional food production.

Acknowledgements: The authors are grateful to University of Food Technologies, Plovdiv, Bulgaria for the institutional support.

\section{References}

1. C. Galanakis, Trends Food Sci. Tech. 26, 68-87 (2012)

2. I. Stefou, S. Grigorakis, S. Loupassaki, D. Makris, Clean Technol. Environ. Policy 21, 1569-1574 (2019)

3. T. Ly, C. Hazama, M. Shimoyamada, H. Ando, K. Kato, R. Yamauchi, J. Agric. Food Chem. 53, 81838189 (2005)

4. V. Benítez, E. Mollá, M. Martin-Cbrejas, Y. Aguilera, F. Lopéz-Andréu, K. Cools, L. Terry, R. Esteban, Plant Foods Hum. Nutr. 66, 48-57 (2011)

5. M. Machavarapu, M. Sindiri, M. Vangalapati, Int. J. Innov. Res. Sci. Eng. Technol. 2, 3125-3129 (2013)

6. K. Sharma, N. Mahato, S. Nile, E. Lee, Y. Lee, Food Func. 7, 3354 (2016)

7. T. Prokopov, A. Slavov, N. Petkova, V. Yanakieva, B. Bozadzhiev, D. Taneva, Acta Alim. 47, 181-188 (2018)

8. T. Piechowak, K. Grzelak-Blaszczyk, R. Bonikowski, M. Balawejder, LWT - Food Sci. Technoil. 117, 108614 (2020)

9. V. Singh, P. Krishan, R. Shri, J. Pharmacogn. Phytochem. 6, 502-505 (2017)

10. Ó. Benito-Román,B.Blanco, M. T. Sanz, S. Beltrán, Food and Bioprod. Proc. 130, 92-105, (2021)

11. Z. Khiary, D. Makris, P. Kefalos, Food Bioproc. Tech. 2, 337-343 (2009)

12. P. Katsampa, E. Valsamedou, S. Grigoracis, D. Markis, Ind. Crops Prod. 77, 535-543 (2015)

13. L. Campone, R. Celano, A. Piccinelli, I. Pagano, S. Carabetta, R. Sonzo, M. Russo, E. Ibanez, A. Cifuentes, L. Rastrelli, Food Chem. 269, 495-502 (2018)

14. D. Makris, P. Kefalas, Acta Alim. 44, 482-492 (2015)

15. M. Nikolova, T. Prokopov, D. Taneva, N. Dimitrov Food Sci. Technol. 13, 65-70 (2019)

16. G. Box, W. Behnken, Technometrics. 2, 455-475 (1960)

17. K. Anbalagan, M. Kumar, K. Ilango, R. Mohankumar, R. Priya, Ind. Crop. Prod. 140, 111703 (2019)

18. V. Gandova, S. Tasheva, V. Popova, T. Ivanova, A. Stoyanova, Proc. Nat. Youth Forum Sci. Technol. Innov. Bus., Plovdiv (1), 45-49 (2019)

19. S. Tasheva, V. Gandova, V. Popova, T. Ivanova, S. Damianova, A. Stoyanova, IOP Conf. Ser.: Mater. Sci. Eng. 595, 012047 (2019)

20. S. Tasheva, V. Popova, V. Gandova, T. Ivanova, Proc. Nat. Youth Forum Sci. Technol. Innov. Bus., Plovdiv (1), 160-165 (2019)

21. S. Tasheva, V. Gandova, V. Popova, T. Ivanova, A. Stoyanova, Proc. 7th Int. Conf. Ener. Effic. Agric. Eng. (EE\&AE), 1-4 (2020) 
22. S. Tasheva, V. Gandova, S. Damianova, A. Stoyanova, J. Chem. Technol. Metall. 55, 45-51 (2020)

23. Z. Khiary, D. Makris, P. Kefalos, Food Sci. Tech. Int. 14, 0497-0502 (2008)

24. J. Novák, S. Labík, I. Malijevská, Physical chemistry in brief (Institute of Chemical Technology, Prague, 2005)

25. J. Masime, E. Ogur, B. Mbatia, A. Aluoch, G. Otieno, J. Sci. Aciev. 2, 43-50 (2017)

26. F. Mogaddasi, M. Heravi, M. Bozorgmehr, P. Ardalan, T. Ardalan, Asian J. Chem. 22, 5093-5100 (2010)

27. P. Umamaheshwari, P. Dinesh Sankar Reddy, IJSR 5, 1243-1246 (2016)

28. E. Jin, S. Lim, S. Kim, Y-S. Park, J. Jank, M-S. Chung, H. Park, K-S. Shim, Food Sci. Biotechnol. 20, 1727-1733 (2011) 